\title{
Adverse maternal outcomes and birth weight discordance in twin gestation: British Columbia, Canadian data
}

This article was published in the following Dove Press journal: International Journal of Women's Health

\author{
Shayesteh Jahanfar' \\ Kenneth Lim² $^{2}$ \\ 'Department of Community Health, \\ Central Michigan University, Mount \\ Pleasant, MI, USA; ${ }^{2}$ Division of \\ Maternal Fetal Medicine, British \\ Columbia Women's Hospital, \\ Vancouver, BC, Canada
}

Objective: The aim of this study was to determine whether twin pregnancies with birth weight discordance were associated with higher rates of maternal morbidities.

Study design: A large retrospective population-based cohort study of twins born in British Columbia, Canada, from 2000 to 2010 was performed. Maternal morbidities and growth discordant were evaluated.

Results: There were 6,328 twin deliveries during the study period. Pregnancies carrying growth-discordant twins had higher frequencies of hypertension disorders, preterm labor, and cesarean delivery compared with growth-concordant twins. They also stayed longer than 3 days in hospital. Multivariate generalized estimating equation modeling found higher odds of preeclampsia, pregnancy-induced hypertension, preterm delivery, and cesarean delivery in mothers carrying growth-discordant twins compared with those carrying growth-concordant category. The modeling also resulted in higher odds in the length of stay longer than 3 days in mothers carrying growth-discordant twins compared with those carrying growth-concordant twins after adjustment for chorionicity.

Conclusion: Maternal complications are associated with growth discordance. Screening for birth weight discordance during pregnancy may alert clinicians to predict subclinical maternal conditions.

Keywords: length of stay, retrospective, maternal morbidity

\section{Introduction}

Maternal morbidity rates escalate with an increase in the incidence of twin gestation. ${ }^{1}$ Because of the inherited biological factors, higher rates of maternal morbidities are reported in multiple gestations compared to singletons. ${ }^{2}$ Major morbidities include increased rates of hypertensive disorders, preeclampsia, proteinuria, gestational diabetes, and first and third trimester bleedings. ${ }^{2,3}$ Besides the rise of antepartum complications in twin gestations, the delivery of twins is also complicated by intrapartum impediments with higher risks of preterm birth, premature rupture of membrane (PROM), prolonged premature rupture of membrane (PPROM), and malpresentation. Given these high rates of complications, a greater number of cesarean sections are established in twin pregnancies compared with singleton gestation. ${ }^{4}$ The national Canadian average for cesarean section (CS) is $26.9 \%$, most of which relate to twin gestations. Because of the higher incidence of maternal morbidities and CD in twin gestations, mothers' stay in hospital is prolonged. As a consequence, health care expenses for multiple pregnancies are approximately five times more than those of singleton pregnancies. ${ }^{5}$
Correspondence: Shayesteh Jahanfa School of Health Sciences, Building 2212, Room 2239, Central Michigan University, Mount Pleasant, MI 48859, USA

Email jahan2s@cmich.edu 
Unequal size of fetuses, a frequent complication of twin gestation, is known to be associated with maternal morbidity. ${ }^{6}$ Birth weight discordance (BWD) may result from a combination of "intrinsic variations" between twins themselves because of unequal provision of nutrients to the fetuses (placenta sharing, cord insertion abnormalities) or from "extrinsic factors" (maternal complications) that affect the fetal growth. Examples of extrinsic factors are pregnancy induced hypertension (PIH), diabetes, and preeclampsia. Preeclamptic twin pregnancies have been found to result in higher rates of small-for-gestational-age neonates among second twins than those with normal blood pressure. ${ }^{7}$ Maternal conditions such as preexisting hypertension (odds ratio [OR] 1.32, 95\% confidence interval [CI] 1.12, 1.56), preeclampsia (OR 1.31, 95\% CI 1.24, 1.38), and diabetes (OR 1.13, 95\% CI 1.04, 1.24) are found to be associated with BWD. ${ }^{8}$

The literature predicting maternal adverse outcomes among women with multiple gestations is scarce. A large number of earlier studies have examined the adverse perinatal outcomes of BWD, but few studies have focused on maternal complications as outcomes. Maternal complications are traditionally used as confounding factors to establish an association between BWD and perinatal conditions. Given that BWD is the result of maternal complications, informative screening of BWD via ultrasound can guide clinicians to look for subclinical symptoms of adverse maternal outcomes.

From the studies that have examined maternal endpoints, none has utilized generalized estimation equation (GEE) to consider the cluster nature of twin data for variables related to twins such as sex. The majority of previous studies are hospital based and small in size. The present populationbased study addresses a number of variables incorporating potential confounding factors such as maternal characteristics, obstetric history, and sex of twins. Unlike previous studies, this study considered maternal outcomes as the outcomes and BWD as the predicting variable. The aim of this study was to determine whether twin pregnancies with BWD were associated with higher rates of maternal morbidities compared with those that did not have BWD.

\section{Methods}

A historic cohort study was carried out to examine the association between BWD and adverse maternal outcomes among all twin pregnancies registered in British Columbia (BC) during the period between 2000 and 2010 ( $n=12,656$ twins or 6,328 twin pairs). We conducted a retrospective population-based cohort study of twins delivered during the period of 2000 through 2010 in the British Columbia (BC), Canada. Data was obtained from Perinatal Services BC's Perinatal Data Registry. ${ }^{47}$ A subsample of this cohort from BC Children and Women Hospital $(\mathrm{C} \& \mathrm{~W})$ contained placental and cord pathology data (1,493 gestations, $\mathrm{n}=2,986$ ).

This study included mothers with gestational age of 20 weeks and longer with twin pregnancy in the analysis. Cases with major structural congenital anomaly, twin to twin transfusion syndrome, those with $<500 \mathrm{~g}$ birth weight and single stillbirth, were excluded. For $\mathrm{C} \& \mathrm{~W}$ cohort cases with reduction procedures, papyrus placentas, and vanishing twins were also excluded. Information regarding data collection is explained elsewhere. ${ }^{9}$

The analytical data set includes information obtained from socio-demographic characteristics of the mothers (age, education, smoking habits, and prepregnancy weight) and infants (sex, birth weight, and gestational age), obstetric information (eg, parity, antenatal visits, and a history of babies with conditions such as low birth weight, macrosomia, congenital anomaly, stillbirth, or neonatal death), medical information (eg, history of hypertension, prior insulin-dependent or noninsulin-dependent diabetes), and complications of pregnancy and labor. It should be noted some variables were added to the PSBC data set after 2004 (eg, maternal education) or after 2008 (eg, IVF).

The main outcome variables were categorized into five groups: outcome variables related to hypertensive conditions as diagnosed by attending physician (preeclampsia, $\mathrm{PIH}$, hypertension during pregnancy, being on prescription medication for hypertensive conditions, and proteinuria), diabetes (abnormal glucose factor during pregnancy, gestational diabetes, and insulin-dependent and non-insulindependent diabetes in pregnancy), antepartum bleeding, delivery (preterm birth, PROM, PPROM, CS), total length of stay in hospital (LOS $>3$ days, defined as length of time between admission and discharge), antepartum length of stay (antepartum LOS $>1$ day, defined as length of time between admission and delivery of baby [a]) and postpartum length of stay (postpartum LOS $>1$ day, defined as length of time between delivery of baby [b] and discharge).

Variables analyzed as covariate or confounders were inclusive of maternal, fetal characteristics and obstetric history. Preterm delivery is defined as a delivery which occurs before 37 completed weeks gestation. Premature rupture of membrane is defined as rupture of the membrane of the amniotic sac and chorion more than one hour before the onset of labor. Prolonged rupture of membrane is calculated from time 
and date of rupture of membrane and is defined as rupture of membrane longer than 18 hours. A hypertensive mother is defined as mother who has antepartum blood pressure of $\geq 140 / 90$ on two consecutive readings during the current pregnancy and prior to first stage labour. Mothers on hypertensive drugs are those who received antihypertensive drugs during current pregnancy (antepartum). Hypertension due to other reasons is defined as hypertension from another cause (not pregnancy induced or hypertensive renal disease) in the current pregnancy, eg, pre-existing essential hypertension. Generalized estimating equation modeling was performed to ascertain various risk factors for maternal outcomes taking the cluster nature of twin data into consideration. Since fetal growth and sex of both twins were used as covariates in the models, clustering of twinning within mothers was necessary to prevent overestimation of the effect. ${ }^{10}$ The study was approved by Ethics Review Board of University of British Columbia, Vancouver (H11-03281). The Ethics Review Board deemed patient consent not necessary due to the retrospective nature of this study.

\section{Results}

There were 12,656 twin births ( $>20$ weeks) or 6,328 twin gestations in BC within 2000-2010. More than 5\% of the twins had $\geq 30 \%$ BWD. More than $5 \%$ of the twins had $\geq 30 \%$ BWD.

Tables 1 and 2 summarize the frequencies of selected maternal characteristics by BWD. Maternal age, gestational age, number of antenatal visits and number of primigravida mothers was found to be significantly different between twin gestations with and without BWD (all $P=0.01$, see Table 1). The distribution of maternal education was different between growth-concordant and growth-discordant twins.

The most common maternal outcomes were LOS $>3$ days $(83.2 \%)$ in hospital, CS (66.2\%), preterm delivery (60.9\%), PROM (47.1\%) followed by PIH (15.1\%). The frequencies of other adverse maternal outcomes were less than $11 \%$.

The frequencies of the following outcomes were higher in growth-discordant ( $\geq 30 \%$ ) gestations: PIH, preeclampsia, hypertension during pregnancy, use of hypertensive medication, PROM, and proteinuria. Gestational diabetes was higher among mothers with growth-concordant twins. The proportions of CS and preterm birth were higher in discordant gestations. Mothers with discordant twin pairs stayed longer in hospital during the antepartum.

Table 3 presents crude and adjusted OR and 95\% CI of adverse maternal outcomes. In a multivariate GEE model where all potential risk factors were included in the model, it was found that the odds of preeclampsia were $2.22(95 \%$ CI 1.04, 4.73), as compared to concordant twins.

The odds of PIH, preterm labor, and CS increased in the growth-discordant group compared with the reference group. The odds of PROM and PPROM days were $<1.0$ but remained statistically significant after adjusting for confounders in discordant gestations compared with concordant ones.

Analyses restricted to sex-discordant twins showed that mothers of twins of growth-discordant twins (with $\geq 30 \%$ BWD) were significantly more likely to be hypertensive $(2.15,95 \%$ CI $1.37,3.36)$ and were about two times more likely to suffer from PIH. Additionally, mothers of discordant twins were more likely to experience preterm birth and were less likely to have premature rupture of membrane (Table 4).

\section{Subgroup analysis adjusted for chorionicity}

This study was able to use chorionicity information on a portion of the data (mothers delivered at C\&W hospital) in

Table I Maternal and fetal characteristics of growth-discordant and growth-concordant twins, delivered in British Columbia ( $n=6,328$ twin gestations)

\begin{tabular}{|c|c|c|c|}
\hline Maternal characteristics & $\begin{array}{l}\text { BWD }<\mathbf{3 0} \% \\
\mathbf{N}=\mathbf{6}, 102 \text { twin } \\
\text { gestations }\end{array}$ & $\begin{array}{l}\text { BWD } \geq 30 \% \\
\mathbf{N}=226 \text { twin } \\
\text { gestations }\end{array}$ & $P$-value \\
\hline Maternal age (years) & $31.64 \pm 5.64$ & $31.76 \pm 6.48$ & 0.01 \\
\hline Gestational age (week) & $31.76 \pm 6.48$ & $33.5 I \pm 3.81$ & 0.01 \\
\hline Maternal education & $14.62 \pm 2.85$ & $14.67 \pm 2.66$ & 0.93 \\
\hline Pregnancy weight gain (kg) & $18.60 \pm 7.46$ & $17.85 \pm 7.47$ & 0.12 \\
\hline Number of antenatal visits & $8.96 \pm 3.59$ & $8.15 \pm 3.80$ & 0.01 \\
\hline Primigravida & $2,998(49.1)$ & $143(63.3)$ & 0.01 \\
\hline \multicolumn{4}{|l|}{ Sex discordance } \\
\hline Discordant & $4,192(68.7)$ & $142(62.8)$ & 0.19 \\
\hline \multicolumn{4}{|l|}{ Smoking } \\
\hline Current & $573(9.4)$ & $155(68.5)$ & 0.08 \\
\hline Former & $415(6.8)$ & 27 (II.9) & \\
\hline Non-smoker & $5,114(83.8)$ & $44(19.4)$ & \\
\hline Fetal characteristics & $\begin{array}{l}\text { BWD }<30 \% \\
\mathbf{N}=1 \mathbf{2}, \mathbf{2 0 4} \\
\text { twins }\end{array}$ & $\begin{array}{l}\text { BWD } \geq 30 \% \\
N=452 \\
\text { twins }\end{array}$ & $P$-value \\
\hline \multicolumn{4}{|l|}{ Fetal sex } \\
\hline Male & $6,144(50.3)$ & $223(49.3)$ & 0.96 \\
\hline \multicolumn{4}{|l|}{ Growth classification } \\
\hline SGA & $365(3.0)$ & 54 (II.9) & 0.01 \\
\hline AGA & $9,109(74.6)$ & $285(63.1)$ & \\
\hline LGA & $2,730(22.4)$ & $113(25.0)$ & \\
\hline
\end{tabular}

Notes: Data presented as mean \pm SD and $\mathrm{n}(\%)$. Data for education collected after April 2004 only. For Education $72 \%$ of data is missing, $21 \%$ of weight gain, 13\% of antenatal visits and $67 \%$ of smoking are missing.

Abbreviations: BWD, birth weight discordance; SGA, small for gestational age; AGA, appropriate for gestational age; LGA, large for gestational age. 
Table 2 Comparing maternal outcomes for twin gestations registered in British Columbia in relation to BWD $\geq 30 \%$ ( $=6,328$ twin gestation)

\begin{tabular}{|c|c|c|c|c|}
\hline \multirow[t]{2}{*}{ Maternal morbidity } & Overall & $<\mathbf{3 0} \%$ & $\geq \mathbf{3 0} \%$ & $\mathbf{X}^{2}$ \\
\hline & 6,328 & 6,102 & 226 & test \\
\hline \multicolumn{5}{|l|}{ Hypertensive conditions } \\
\hline Preeclampsia & $152(2.4)$ & $140(2.3)$ & $12(5.3)$ & 0.01 \\
\hline Pregnancy induced hypertension & $953(15.1)$ & $902(14.8)$ & $51(22.6)$ & 0.01 \\
\hline Hypertension* & $406(6.4)$ & $380(6.2)$ & $26(11.5)$ & 0.01 \\
\hline On antihypertensive drugs $* *$ & $201(3.2)$ & $185(3.0)$ & $16(7.1)$ & 0.01 \\
\hline Hypertension due to other causes*** & $174(2.7)$ & $<5(<0.1)$ & $169(74.8)$ & 0.53 \\
\hline Proteinuria & $312(4.9)$ & $295(4.8)$ & $17(7.5)$ & 0.01 \\
\hline \multicolumn{5}{|l|}{ Bleeding } \\
\hline Antepartum bleeding & $169(2.7)$ & I $64(2.7)$ & $<5(<2.2)$ & 0.53 \\
\hline Bleeding prior to 20 weeks & $201(3.2)$ & $196(3.2)$ & $<5(<2.2)$ & 0.23 \\
\hline \multicolumn{5}{|l|}{ Delivery } \\
\hline Preterm delivery & $3,851(60.9)$ & $3,670(60.1)$ & $18 \mid(80.1)$ & 0.01 \\
\hline PROM & $2,979(47.1)$ & $2,912(47.7)$ & $67(29.6)$ & 0.01 \\
\hline Prolonged PROM & $429(6.8)$ & $418(6.9)$ & II (4.9) & 0.71 \\
\hline Cesarean section & $4,186(66.2)$ & $4,011(65.7)$ & $175(77.4)$ & 0.01 \\
\hline \multicolumn{5}{|l|}{ Diabetes } \\
\hline Abnormal glucose factor & $149(2.4)$ & $144(2.4)$ & $<5(<2.2)$ & 0.83 \\
\hline Gestational diabetes & $677(10.7)$ & $660(10.8)$ & $17(7.5)$ & 0.03 \\
\hline Insulin-dependent diabetes & $20(0.3)$ & $19(0.3)$ & $<5(<0.4)$ & 0.62 \\
\hline Non-insulin-dependent diabetes & $<5(<0.1)$ & $<5(<0.1)$ & $0(0.0)$ & - \\
\hline \multicolumn{5}{|l|}{ Admission } \\
\hline Total LOS in hospital $>3$ days & $5,267(83.2)$ & $5,076(83.2)$ & $191(84.5)$ & 0.14 \\
\hline Prior to delivery admission $* * * *$ & $1,836(29.0)$ & $1,770(29.0)$ & $66(29.2)$ & 0.92 \\
\hline Antepartum LOS $>$ I day & $\mathrm{I}, 406(22.2)$ & $1,328(21.8)$ & $78(34.5)$ & 0.01 \\
\hline Postpartum LOS $>$ I day & $6,129(96.9)$ & $5,916(96.9)$ & $213(94.2)$ & 0.01 \\
\hline
\end{tabular}

Notes: Data presented as $n(\%)$. *Mother has antepartum blood pressure of $\geq 140 / 90$ on two consecutive readings during the current pregnancy and prior to first stage labor. **Mother received antihypertensive drugs during current pregnancy (antepartum). ****Mother had hypertension from another cause (not pregnancy-induced or hypertensive renal disease) in the current pregnancy, for example, preexisting essential hypertension. ****Number of prior inpatient hospital admissions during this pregnancy for any reason. PROM is defined as rupture of the membrane of the amniotic sac and chorion more than one hour before the onset of labor. Prolonged PROM is calculated from time and date of rupture of membrane and is defined as rupture of membrane longer than 18 hours. Total LOS in hospital $>3$ days is defined as length of time between admission and discharge; antepartum LOS $>$ I day is defined as length of time between admission and delivery of baby; and postpartum LOS >I day is defined as length of time between delivery of baby and discharge.

Abbreviations: LOS, length of stay; PROM, premature rupture of membrane; PPROM, prolonged premature rupture of membrane; BWD, birth weight discordance.

order to make further adjustments to the relationship between growth discordance and maternal outcomes (Table 5). Similar results were found in this analysis as for the provincial database.

The increased odds of preeclampsia for growth-discordant gestations compared with concordant ones were not statistically significant while odds of PIH and hypertension were two times higher in growth-discordant twins. The direction of odds for PROM and PPROM was reversed. The odds of PROM were $71 \%(95 \%$ CI 1.06, 2.72) higher in growthdiscordant gestations compared with growth-concordant gestations, and the odds of PPROM were $>2.5$ times higher in growth-discordant gestations compared with the reference category.

The adjusted odds of CS for chorionicity remained high and significant $(3.73,95 \%$ CI 2.13-6.52).

In growth-discordant gestations, length of stay $>3$ days in hospital adjusted for chorionicity was 3.55 times as likely as in concordant gestations (95\% CI 1.29-9.79).

\section{Discussion}

This study found a strong association between twins' growth discordance and hypertensive disorders of the mother, including preeclampsia, $\mathrm{PIH}$, hypertension, and proteinuria. This finding is consistent with the literature..$^{7,8,11-13}$ A subgroup analysis of opposite-sex twins as a proxy measure for chorionicity was conducted, and an increased risk of PIH and hypertension in growth-discordant twins was found. A retrospective study indicated that mothers with dichorionic twins were twice as likely to develop mild preeclampsia compared with those with monochorionic twins. ${ }^{14}$

The underlying reason for the association between BWD and hypertensive disorders is yet to be researched. Growth differences between twins may be due to the increased demand imposed by twins and placenta ischemia/ hypoxia. ${ }^{15}$ Placenta hypoxia is thought to lead to widespread activation/dysfunction of the maternal vascular endothelium, which in turn results in increased formation of proteins (eg, endothelin, thromboxane, and superoxide), constricting 
Table 3 Multivariate analysis of fetal, neonatal, and maternal outcomes of growth-concordant $(<30 \%)$ versus growth-discordant twins with $\geq 30 \%$ BWD (6,328 gestations, $n=12,656$ twins)

\begin{tabular}{|c|c|c|}
\hline Maternal morbidity & Crude OR & Adjusted OR \\
\hline \multicolumn{3}{|l|}{ Hypertensive disorders } \\
\hline Preeclampsia & $2.19(1.04-4.58)$ & $2.22(1.04-4.73)$ \\
\hline Pregnancy-induced hypertension & $1.53(1.02-2.32)$ & $1.63(1.08-2.47)$ \\
\hline Hypertension* & $1.44(0.82-2.53)$ & $1.54(0.87-2.72)$ \\
\hline Proteinuria & $1.66(0.90-3.05)$ & $1.67(0.90-3.08)$ \\
\hline \multicolumn{3}{|l|}{ Bleeding } \\
\hline Antepa & $1.18(0.42-3.31)$ & $0.76(0.29-2.00)$ \\
\hline \multicolumn{3}{|l|}{ Delivery } \\
\hline Preterm c & 2.66 & 2.27 \\
\hline PROM & 0.36 & 0.46 \\
\hline PPROM & $0-1.23)$ & $4-0.95)$ \\
\hline Caesarea & 4) & $-1.74)$ \\
\hline \multicolumn{3}{|l|}{ Diabetes } \\
\hline Gestational & $0.68(0.5 I-0.9 I)$ & $0.67(0.50-0.91)$ \\
\hline \multicolumn{3}{|l|}{ Admission } \\
\hline Total LOS in hospital $>3$ days & I.I5 (0.7I-I.87) & I.I6 (0.72-I.87) \\
\hline Prior to delivery admission** & $1.24(1.05-1.46)$ & $1.05(0.89-1.25)$ \\
\hline Antepartum LOS $>$ I day & $1.41(0.98-2.04)$ & $0.95(0.64-1.40)$ \\
\hline Postpartum LOS > I day & $0.68(0.29-1.57)$ & $1.62(0.62-4.20)$ \\
\hline
\end{tabular}

Notes: Data presented as odds ratio ( $95 \%$ confidence interval). *Mother has antepartum blood pressure of $\geq 140 / 90$ on two consecutive readings during the current pregnancy and prior to first stage labor. ${ }^{* *}$ Number of prior inpatient hospital admissions during this pregnancy for any reason. Total LOS in hospital $>3$ days is defined as length of time between admission and discharge; antepartum LOS >I day is defined as length of time between admission and delivery; and postpartum LOS $>I$ day is defined as length of time between delivery and discharge. PROM is defined as rupture of the membrane of the amniotic sac and chorion more than one hour before the onset of labor. Prolonged PROM is calculated from time and date of rupture of membrane and is defined as rupture of membrane longer than 18 hours. Abbreviations: OR, odds ratio; PROM, premature rupture of membrane; PPROM, prolonged premature rupture of membrane; BWD, birth weight discordance; LOS, length of stay.

Table 4 Multivariate analysis of maternal outcomes of concordant $(<30 \%)$ versus discordant twins with $\geq 30 \%$ BWD among a subgroup of sex-discordant twins (2,167 gestations, $n=4,334)$

\begin{tabular}{|c|c|c|}
\hline Maternal morbidity & Crude OR & Adjusted OR \\
\hline \multicolumn{3}{|l|}{ Hypertensive disorders } \\
\hline Preeclampsia & $1.12(0.40-3.07)$ & I.0I (0.37-2.77) \\
\hline Pregnancy-induced hypertension & $1.95(1.40-2.73)$ & $1.99(1.42-2.79)$ \\
\hline Hypertension* & $2.25(1.06-2.04)$ & $2.15(1.37-3.36)$ \\
\hline Proteinuria & $1.37(0.78-2.37)$ & $1.29(0.73-2.27)$ \\
\hline \multicolumn{3}{|l|}{ Bleeding } \\
\hline Antepartun & $0.33(0.08-1.36)$ & $0.21(0.05-0.85)$ \\
\hline \multicolumn{3}{|l|}{ Delivery } \\
\hline Preterm labor & $2.12(1.50-2.98)$ & $1.82(1.28-2.60)$ \\
\hline PROM & $0.57(0.36-0.88)$ & $0.60(0.38-0.95)$ \\
\hline PPROM & $0.85(0.44-1.67)$ & $0.72(0.35-1.45)$ \\
\hline Caesarean de & I.20 (0.87-I.66) & $\mathrm{I} .47(0.9 \mathrm{I}-2.40)$ \\
\hline \multicolumn{3}{|l|}{ Diabetes } \\
\hline Gestation & $0.66(0.82-1.96)$ & $0.7 \mid(0.3|-| .6 \mid$ \\
\hline \multicolumn{3}{|l|}{ Admission } \\
\hline Total LOS in & $0.89(0.46-\mid .7 I)$ & $0.87(0.42-1.81)$ \\
\hline Prior to delivery admission** & $1.09(0.62-1.88)$ & $0.96(0.54-1.72)$ \\
\hline
\end{tabular}

Notes: Data presented as odds ratio ( $95 \%$ confidence interval). *Mother has antepartum blood pressure of $\geq 140 / 90$ on two consecutive readings during the current pregnancy and prior to first stage labor. **Number of prior inpatient hospital admissions during this pregnancy for any reason. Total LOS in hospital $>3$ days is defined as length of time between admission and discharge. PROM is defined as rupture of the membrane of the amniotic sac and chorion more than one hour before the onset of labor. Prolonged PROM is calculated from time and date of rupture of membrane and is defined as rupture of membrane longer than 18 hours.

Abbreviations: LOS, length of stay; OR, odds ratio; PROM, premature rupture of membrane; PPROM, prolonged premature rupture of membrane; BWD, birth weight discordance.
Table 5 Multivariate analysis of maternal outcomes of mothers with BWD ( $<30 \%$ ) versus $\geq 30 \%$ BWD in mothers who delivered at C\&W hospital $(1,493$ gestations, $n=2,986)$

\begin{tabular}{|c|c|c|}
\hline Maternal morbidity & Crude OR & Adjusted OR \\
\hline \multicolumn{3}{|l|}{ Hypertensive disorders } \\
\hline Preeclampsia & $2.52(0.29-21.82)$ & $2.13(0.42-10.57)$ \\
\hline Pregnancy-induced hypertension & 1.95 (1.23-3.07) & $2.01(1.26-3.17)$ \\
\hline Hypertension* & $2.09(1.22-3.58)$ & $2.11(1.22-3.64)$ \\
\hline Proteinuria & $1.50(0.74-3.02)$ & $\mathrm{I} .55(0.76-3.15)$ \\
\hline \multicolumn{3}{|l|}{ Bleeding } \\
\hline Antepartum bleeding & $0.68(0.26-1.80)$ & $0.5 \mathrm{I}(0.19-1.38)$ \\
\hline \multicolumn{3}{|l|}{ Delivery } \\
\hline Preterm labor & $2.77(1.65-4.64)$ & $2.63(1.57-4.4 I)$ \\
\hline PROM & $1.82(1.13-2.92)$ & $1.71(1.06-2.72)$ \\
\hline PPROM & $2.84(1.77-4.56)$ & $2.65(1.65-4.25)$ \\
\hline Caesarean delivery & $3.22(1.85-5.6 I)$ & $3.73(2.13-6.52)$ \\
\hline \multicolumn{3}{|l|}{ Diabetes } \\
\hline Gestational diabetes & $1.09(0.63-1.88)$ & $\mathrm{I} .06(0.6 \mathrm{I}-\mathrm{I} .85)$ \\
\hline \multicolumn{3}{|l|}{ Admission } \\
\hline Total LOS in hospital $>3$ days & $3.71(1.35-10.20)$ & $3.55(1.29-9.76)$ \\
\hline Prior to delivery admission** & $1.27(0.84-1.92)$ & $0.97(0.62-|.5|)$ \\
\hline
\end{tabular}

Notes: Data presented as odds ratio ( $95 \%$ confidence interval). Reference category: $<30 \%$. *Mother has antepartum blood pressure of $\geq 140 / 90$ on two consecutive readings during the current pregnancy and prior to first stage labor. **Number of prior inpatient hospital admissions during this pregnancy for any reason. Total LOS in hospital $>3$ days is defined as length of time between admission and discharge. PROM is defined as rupture of the membrane of the amniotic sac and chorion more than one hour before the onset of labor. Prolonged PROM is calculated from time and date of rupture of membrane and is defined as rupture of membrane longer than 18 hours.

Abbreviations: LOS, length of stay; OR, odds ratio; PROM, premature rupture of membrane; PPROM, prolonged premature rupture of membrane; BWD, birth weight discordance.

blood vessels, and raising blood pressure. ${ }^{16}$ For twin pregnancies with no fetal growth restriction, an increased level of antiangiogenic protein soluble fms-like tyrosine kinase is reported in preeclamptic mothers with twin gestations, which is related to increased placental mass in twins rather than placenta pathology. ${ }^{17}$

Other endocrine and metabolic mechanisms that are postulated to contribute to the pathogenesis of preeclampsia are not specific to twin gestations. Apart from maternal characteristics such as nulliparity and extremes of maternal age, various endocrine and metabolic conditions are found to be associated with preeclampsia. ${ }^{18}$ Endocrine conditions include diabetes. Metabolic conditions include abnormalities in uric acid clearance due to decreased glomerular filtration and abnormalities in the renin-angiotensin-aldosterone system.

The proportion of preterm births resulting from multiple gestations in Canada is increased by $25 \% .{ }^{19}$ In BC, the preterm twin birth rate has risen from $5.3 \%$ in 2000 to $6.2 \%$ in $2003 .{ }^{20}$ The incidence of preterm birth was $61 \%$ in our study.

This rise in the rate is driven by an increase in medically indicated preterm birth. ${ }^{21}$ A study of 2,516 twin gestations that occurred among residents of the province of Nova Scotia, 
Canada, between 1988 and 1997 found that an increased risk of preterm labor induction was responsible for the increase in preterm birth. ${ }^{22}$ Labor induction has to be performed in the case of maternal and obstetrical complications. These complications are preeclampsia, diabetes, prior stillbirth, PROM, and PPROM. Other reasons for preterm delivery are augmentation of labor and repeat CS because the patient presents with contractions. ${ }^{23}$ Despite a common agreement over the necessity of pregnancy termination in cases of severe maternal complications, there is not much consensus over the termination timing. ${ }^{24-26} \mathrm{~A}$ higher rate of preterm birth in growthdiscordant twins $(80.3 \%)$ versus concordant twins $(60.1 \%)$ was also found. Adjusting for potential confounders, the odds of preterm labor were found to be higher in discordant twins compared with concordant ones. These findings are consistent with other studies showing a rise in the proportion of babies born too early for a number of reasons. ${ }^{27-29}$ In some cases, birth is attempted to limit maternal risks, while in other cases delivery is pursued mainly for fetal benefit.

Adverse outcomes related to BWD lead to iatrogenic premature pregnancy termination, prematurity-related problems, and greater incidence of $\mathrm{CS}^{30}$ In our study, the CS rate was higher among growth-discordant twin gestations than among concordant pregnancies. Mazhar et $\mathrm{al}^{31}$ reported a higher frequency of CS for growth-discordant twin gestations (29\%) compared to $21 \%$ among the growthconcordant twin pregnancies. Higher rate of CS was also reported in a hospital-based retrospective study by Kilic et $\mathrm{al}^{32}$ who followed 136 preterm deliveries admitted to the NICU between 2003 and 2005 in the Ondojuz Mayis University Hospital, Turkey. The twins were categorized as discordant if the birth weight difference was $>15 \%$. Birth by CS was significantly higher in growth-discordant twins ( $56.1 \%$ versus $77.8 \%$ ) in comparison with growth-concordant twins $(P<0.05)$. A progressively increased rate of CS rate with increasing discordance was also reported by Hollier et al. ${ }^{33}$ Lower rates of CS were also found in other studies ${ }^{34}$ while similar proportions of CS are reported in asymmetric growth-restricted discordant twins, ${ }^{35}$ twins with a $>500 \mathrm{~g}$ birth weight difference, ${ }^{36}$ and twins with lower and higher BWD thresholds. ${ }^{30,37}$

In the present study, the odds of CS were not higher among opposite-sex twins with BWD compared to concordant twins. This finding suggests that the higher rate of CS in twin pregnancy is dependent on chorionicity.

PROM and PPROM are found to be significantly associated with increased early neonatal morbidity, ${ }^{38}$ mortality, ${ }^{39}$ longer maternal hospitalization, ${ }^{40}$ very low birth weight delivery, ${ }^{41}$ and chorioamnioitis. ${ }^{42}$ The analysis of this study shows a statistically significant association between BWD and PPROM. A significant independent association between PROM and BWD was also found. The odds of PROM and PPROM were found to be $<1$, suggesting a protective effect of BWD on the occurrence of PROM/PPROM. This result varies for lower gestational age as the calculated odds were adjusted for this important variable. This result is peculiar and need further adjustment for chorionicity. Consistent with our finding, Mazhar et al's cross-sectional and hospital-based study of 253 twin gestations found a lower proportion of PROM in gestations carrying discordant twins compared with the reference category ( $9 \%$ versus $33 \%, P=0.001) .{ }^{31}$ Kilic et $\mathrm{al}^{32}$ showed that in NICU-admitted preterm growth-discordant twins, PROM was lower than that of concordant pairs (18.5\% versus $29.3 \%$ ). None of these studies controlled for chorionicity. When the data for chorionicity were adjusted, reverse odds of higher values for PROM and PPROM were found.

These findings could be due to the termination of pregnancies carrying growth-discordant twins that are complicated by PROM or PPROM compared with pregnancies with growthconcordant twins. This was confirmed by the higher proportion of CS in growth-discordant twins compared with growthconcordant ones $(77.4 \%$ versus $65.7 \%)$ and the subsequent lower frequency of gestational age of $\geq 37$ weeks in pregnancies carrying growth-discordant twins compared with those carrying growth-concordant twins (22.6\% versus $9.1 \%)$.

In 2002-2003, Canadian hospitals spent an estimated $\$ 821$ million on pregnancy and childbirth services for typical maternal inpatients. ${ }^{43}$ On average, all-cause health care expenses for mothers with twins are 20 times more expensive than that for singleton delivery. ${ }^{44} \mathrm{~A}$ cost analysis study on 1,486 twin pregnancies delivered in the USA found that the majority of delivery cost relates to maternal LOS and hospital charges. Longer maternal LOS was associated with lower gestational age and higher rates of CS and preeclampsia. ${ }^{45}$ Longer neonatal hospital stay has been reported in the literature for twins born with growth discordance compared with growth-concordant twins. ${ }^{46}$ This study investigated the maternal antepartum and postpartum LOS and found a higher frequency of length of stay, as defined in the method section, for mothers carrying growth-discordant twins compared with those carrying growth-concordant twins ( $P=0.001$ for postpartum LOS). Multivariate analysis also found a positive effect of BWD on maternal LOS after adjusting for type of delivery, maternal age, parity, type of anesthesia, chorionicity, and maternal diseases. 


\section{Limitations}

There are several important limitations to this research. First, chorionicity data for twins is not collected in the PSBC Perinatal Data Registry. This study managed to collect and link such information for a quarter of the province-based data. In order to compensate for the lack of chorionicity in the provincial data set, sex discordance was used, which was found important to rely on if pathology data are missing. Second, in the data abstract, we did not request for several variables such as race, household income while there was some missing data for others such as maternal education, smoking and drug habits. Moreover, study was unable to adjust for some variables such as IVF (collected after April 1, 2008), maternal education (collected after April 1, 2004), and as such there is a large proportion of missing data for some variables, which is a limitation of this study. Other variables with significant amounts of missing information are BMI, weight gain, and number of antenatal visits (Table 1). For most part, the percentage of missing data is not large for the variables utilized in the study analysis and small amounts of missing data should not affect our findings. Third, the retrospective nature of this cohort study inherently brings some inevitable limitations such as limited access to potential confounders or missing data. A decade worth of information from a population-based study has potentially eliminated such limitations for many variables, but a Canada-wide study would increase study power.

\section{Conclusion}

This study found higher rates of maternal complications in mothers carrying growth-discordant twins. This indicates that BWD is a predictor of subclinical maternal complications. The key points and the contribution of the current study to literature is that BWD can be considered as a predictor of adverse maternal outcomes. It is therefore recommended that diagnosis of BWD among twins during ultrasound screening may be used to alert clinicians to monitor potential adverse outcomes.

\section{Acknowledgments}

Many thanks to Dr Eugenia Ovideo Joekes, Dr Patricia Spittal and Dr Martin Schechter, the members of thesis research committee for the PhD program. Data source citations: Perinatal Services British Columbia (2012): PSBC. POPDATABC (2015). Data Extract. PSBC(2014).

\section{Disclosure}

All inferences, opinions, and conclusions drawn in this publication are those of the authors, and do not reflect the opinions or policies of the Data Steward(s). The authors report no conflicts of interest in this work.

\section{References}

1. Young BC, Wylie BJ. Effects of twin gestation on maternal morbidity. Semin Perinatol. 2012;36(3):162-168.

2. Vogel JP, Torloni MR, Seuc A, et al. Maternal and perinatal outcomes of twin pregnancy in 23 low- and middle-income countries. PLoS One. 2013;8(8):e70549.

3. Obiechina N, Okolie V, Eleje G, Okechukwu Z, Anemeje O. Twin versus singleton pregnancies: the incidence, pregnancy complications, and obstetric outcomes in a Nigerian tertiary hospital. Int $J$ Womens Health. 2011;3:227-230.

4. Rossi AC, Mullin PM, Chmait RH. Neonatal outcomes of twins according to birth order, presentation and mode of delivery: a systematic review and meta-analysis. BJOG. 2011;118(5):523-532.

5. Lemos EV, Zhang D, Van Voorhis BJ, Hu XH. Healthcare expenses associated with multiple vs singleton pregnancies in the United States. Am J Obstet Gynecol. 2013;209(6):586.e1-586.e11.

6. Mazhar SB, Peerzada A, Ahmud G, Mazhar SB, Peerzada A, Mahmud G. Maternal and perinatal complications in multiple versus singleton pregnancies: a prospective two years study. J Pak Med Assoc. 2002;52(4):143-147.

7. Ferrazzani S, Merola A, De Carolis S, Carducci B, Paradisi G, Caruso A. Birth weight in pre-eclamptic and normotensive twin pregnancies: an analysis of discordance and growth restriction. Hum Reprod. 2000;15(1):210-217.

8. Sannoh S, Demissie K, Balasubramanian B, Rhoads GG. Risk factors for intrapair birth weight discordance in twins. J Matern Fetal Neonatal Med. 2003;13(4):230-236.

9. Jahanfar SLim K, Ovideo-Joekes E. Optimal threshold for birth weight discordance: Does knowledge of chorionicity matter? J Perinatol. 2016;36(9):704-712.

10. Ananth CV, Platt RW, Savitz DA. Regression models for clustered binary responses: implications of ignoring the intracluster correlation in an analysis of perinatal mortality in twin gestations. Ann Epidemiol. 2005;15(4):293-301.

11. Ferrazzani S, Moresi S, Garofalo S, et al. Gestational hypertension and birth weight in twin pregnancies. Pregnancy Hypertens. 2012;2(3) 257-258.

12. Jacobs AR, Demissie K, Jain NJ, et al. Birth weight discordance and adverse fetal and neonatal outcomes among triplets in the United States. Obstet Gynecol. 2003;101(5 Pt 1):909-914.

13. Demissie K, Ananth CV, Martin J, et al. Fetal and neonatal mortality among twin gestations in the United States: the role of intrapair birth weight discordance. Obstet Gynecol. 2002;100(3):474-80.

14. Sparks TN, Rosenstein MG, Cheng YW, Chang JH, Phan N, Caughey AB 612: is twin chorionicity associatied with preeclampsia? Am J Obstet Gynecol. 2011;204(1):S243-S244.

15. Bajoria R, Sooranna SR, Ward S, D'Souza S, Hancock M. Placental transport rather than maternal concentration of amino acids regulates fetal growth in monochorionic twins: implications for fetal origin hypothesis. Am J Obstet Gynecol. 2001;185(5):1239-1246.

16. Granger JP, Alexander BT, Llinas MT, Bennett WA, Khalil RA Pathophysiology of preeclampsia: linking placental ischemia/hypoxia with microvascular dysfunction. Microcirculation. 2002;9(3): 147-160.

17. Rana S, Hacker MR, Modest AM, et al. Circulating angiogenic factors and risk of adverse maternal and perinatal outcomes in twin pregnancies with suspected preeclampsia. Hypertension. 2012;60(2) 451-458.

18. Magon N, Chopra S, Joneja GS. Hypertension in pregnancy: the endocrine and metabolic aspect. Indian J Endocrinol Metab. 2011;15(Suppl 4): S380-S382.

19. Okun N, Pastuzak A, Seaward G, et al. Management of twin pregnancies (part 1). J SOGC. 2000;91:5-15. 
20. Program British Columbia Reproductive care. Preterm labour, Obsetetrics Guideline 2A.; 2005. Available from: http://www. perinatalservicesbc.ca/Documents/Guidelines-Standards/Maternal/ PretermLabourGuideline.pdf. Accessed September 21, 2016.

21. Ananth CV, Vintzileos AM. Medically indicated preterm birth: recognizing the importance of the problem. Clin Perinatol. 2008;35(1): 53-67, viii.

22. Joseph KS, Allen AC, Dodds L, Vincer MJ, Armson BA. Causes and consequences of recent increases in preterm birth among twins. Obstet Gynecol. 2001;98(1):57-64.

23. Spong CY, Mercer BM, D'alton M, Kilpatrick S, Blackwell S, Saade G. Timing of indicated late-preterm and early-term birth. Obstet Gynecol. 2011;118(2 Pt 1):323-333.

24. Clinical practice guideline management of multiple pregnancy. Ireland; 2014. Available from: https:/www.hse.ie/eng/about/Who/ clinical/natclinprog/obsandgynaeprogramme/pregmulti.pdf. Accessed September 21, 2016.

25. ACOG Issues New Guidelines on Managing Stillbirths; 2015. Available from: http:/www.acog.org/About-ACOG/News-Room/ News-Releases/2009/ACOG-Issues-New-Guidelines-on-ManagingStillbirths. Accessed February 11, 2016.

26. Barrett JFR. Twin delivery: method, timing and conduct. Best Pract Res Clin Obstet Gynaecol. 2014;28(2):327-338.

27. Malinowski W, Lipiec W, Partyka J. Twin birth weight discordance and risk of preterm birth. Birth. 2003;7(3 Suppl 1):223-227.

28. Wen SW, Tan H, Walker M. The association between intratwin birthweight discordance and preterm birth in twin pregnancy. Aust $\mathrm{N} \mathrm{ZJ}$ Obstet Gynaecol. 2006;46(5):402-406.

29. Chauhan SP, Scardo JA, Hayes E, Abuhamad AZ, Berghella V. Twins: prevalence, problems, and preterm births. Am J Obstet Gynecol. 2010; 203(4):305-315.

30. Appleton C, Pinto L, Centeno M, Clode N, Cardoso C, M Graça L. Near term twin pregnancy: clinical relevance of weight discordance at birth. J Perinat Med. 2007;35(1):62-66.

31. Mazher SB, Kanwal S. Twin birth weight discordance: associated factors and outcome. J Coll Physicians Surg Pak. 2010;20(6):391-394.

32. Kilic M, Aygun C, Kaynar-Tuncel E, et al. Does birth weight discordance in preterm twins affect neonatal outcome? J Perinatol. 2006;26(5):268-272.

33. Hollier LM, McIntire DD, Leveno KJ. Outcome of twin pregnancies according to intrapair birth weight differences. Obstet Gynecol. 1999;94(6):1006-1010.
34. Blickstein I, Keith LG. Neonatal mortality rates among growthdiscordant twins, classified according to the birth weight of the smaller twin. Am J Obstet Gynecol. 2004;190(1):170-174.

35. Dashe JS, McIntire DD, Santos-Ramos R, Leveno KJ. Impact of head-to-abdominal circumference asymmetry on outcomes in growthdiscordant twins. Am J Obstet Gynecol. 2000;183(5):1082-1087.

36. Juhasz AG, Krasznai Z, Darago P, et al. Management of twin birth. Orv Hetil. 2004;145(49):2485-2489.

37. Mahony R, Mulcahy C, Foley M, Carroll S. Birth weight discordance in twin pregnancy. Does it matter? Int J Gynecol Obstet. 2009;107: S254-S255.

38. Boskabadi H, Maamouri G, Mafinejad S. Neonatal complications related with prolonged rupture of membranes. Maced J Med Sci. 2011;4(1): 93-98.

39. M. J, N. K. Neonatal morbidity and mortality in high risk pregnancies. Med Forum Mon. 2002;13(12):9-13.

40. Gazmararian JA, Petersen IR, Jamieson DJ, et al. Hospitalizations during pregnancy among managed care enrollees. Obstet Gynecol. 2002;100(1):94-100.

41. Mannan MA, Jahan N, Dey SK, Uddin MF, Ahmed S. Maternal and foetal risk factor and complication with immediate outcome during hospital stay of very low birth weight babies. Mymensingh Med J. 2012;21(4):639-647.

42. Bakos O, Cederholm M, Kieler H. Very prolonged membrane rupture and delayed delivery of the second twin. Fetal Diagn Ther. 1998;13(3): 147-149.

43. Giving Birth in Canada: The Costs. Available from: https://secure. cihi.ca/free_products/Costs_Report_06_Eng.pdf. Accessed March 6, 2014

44. Multiple birth pregnancies can cost 20 times more than singletons. ScienceDaily. Available from: http:/www.sciencedaily.com/ releases/2013/11/131111091530.htm. Accessed May 17, 2014.

45. Luke B, Brown MB, Alexandre PK, et al. The cost of twin pregnancy: maternal and neonatal factors. Am J Obstet Gynecol. 2005;192(3): 909-915.

46. Alam Machado RDC, Brizot MDL, Liao AW, et al. Early neonatal morbidity and mortality in growth-discordant twins. Acta Obstet Gynecol Scand. 2009;88(2):167-171.

47. Perinatal Services British Columbia (2012): PSBC. POPDATABC (2015). Data Extract. PSBC (2014).
International Journal of Women's Health

\section{Publish your work in this journal}

The International Journal of Women's Health is an international, peerreviewed open-access journal publishing original research, reports, editorials, reviews and commentaries on all aspects of women's healthcare including gynecology, obstetrics, and breast cancer. The manuscript management system is completely online and includes

\section{Dovepress}

a very quick and fair peer-review system, which is all easy to use. Visit http://www.dovepress.com/testimonials.php to read real quotes from published authors. 